Supporting Information

\title{
Silver(I) Cage and Infinite Chain Stabilized by Bowl-Shaped Resorcin[4]arene Tetraethynide Ligands
}

Xue Han, ${ }^{[a]}$ Shan-Shan Jin, ${ }^{[a]}$ Jian-Fang Ma, ${ }^{[a]}$ Jin Yang, ${ }^{[a]}$ and Thomas C. W. Mak*[b]

${ }^{[\mathrm{a}]}$ Key Lab of Polyoxometalate Science, Department of Chemistry, Northeast Normal University, Changchun 130024, China

${ }^{[\mathrm{b}]}$ Department of Chemistry and Center of Novel Functional Molecules, The Chinese University of Hong Kong, Shatin, New Territories, Hong Kong SAR, China

* Correspondence authors

E-mail: majf247@yahoo.com (J.-F. Ma)

Fax: +86-431-85098620 (J.-F. Ma)

E-mail: tcwmak@cuhk.edu.hk (T. C.W.Mak) 

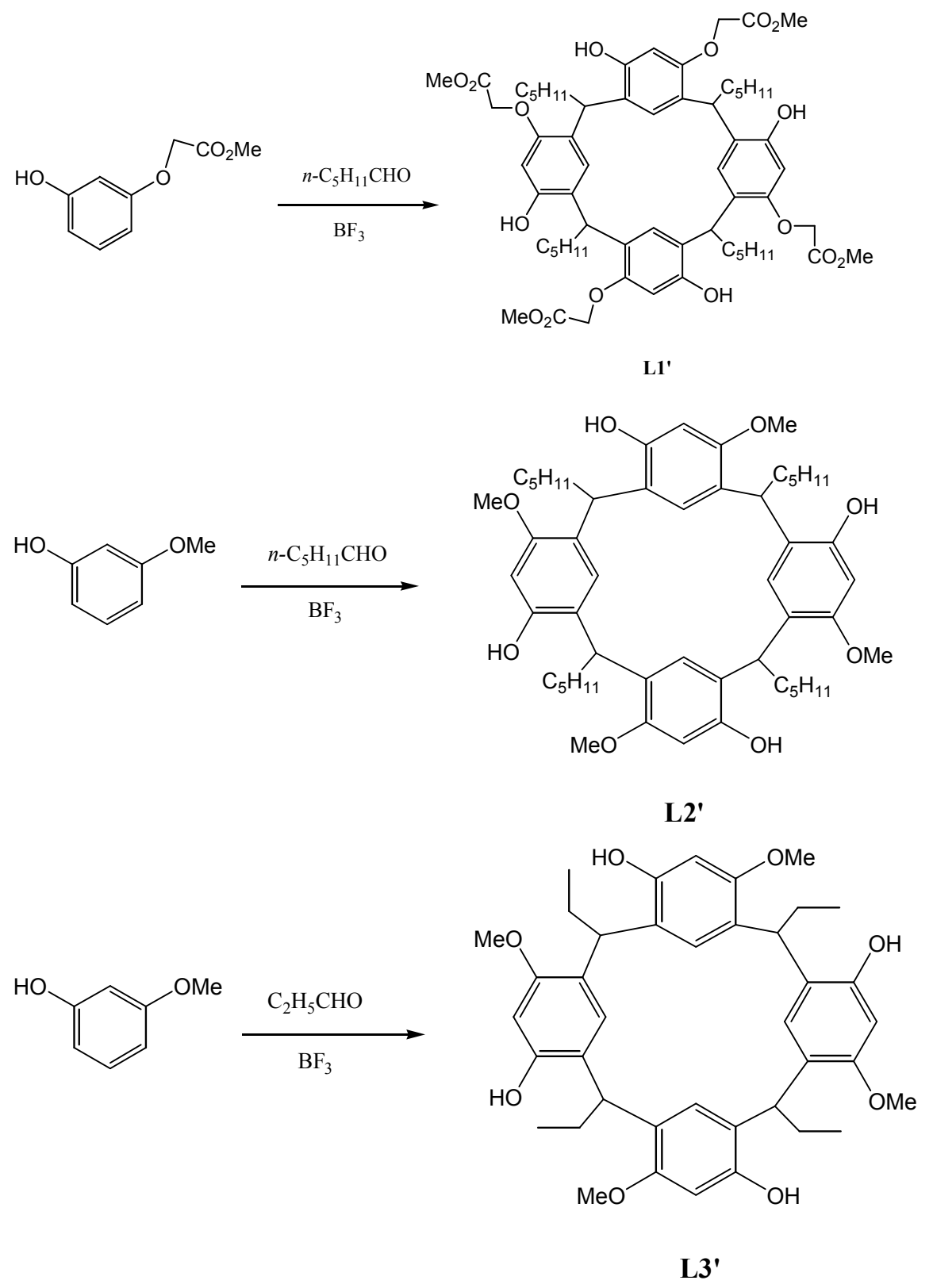

Scheme S1. Synthetic Procedure of L1', L2' and L3'. 


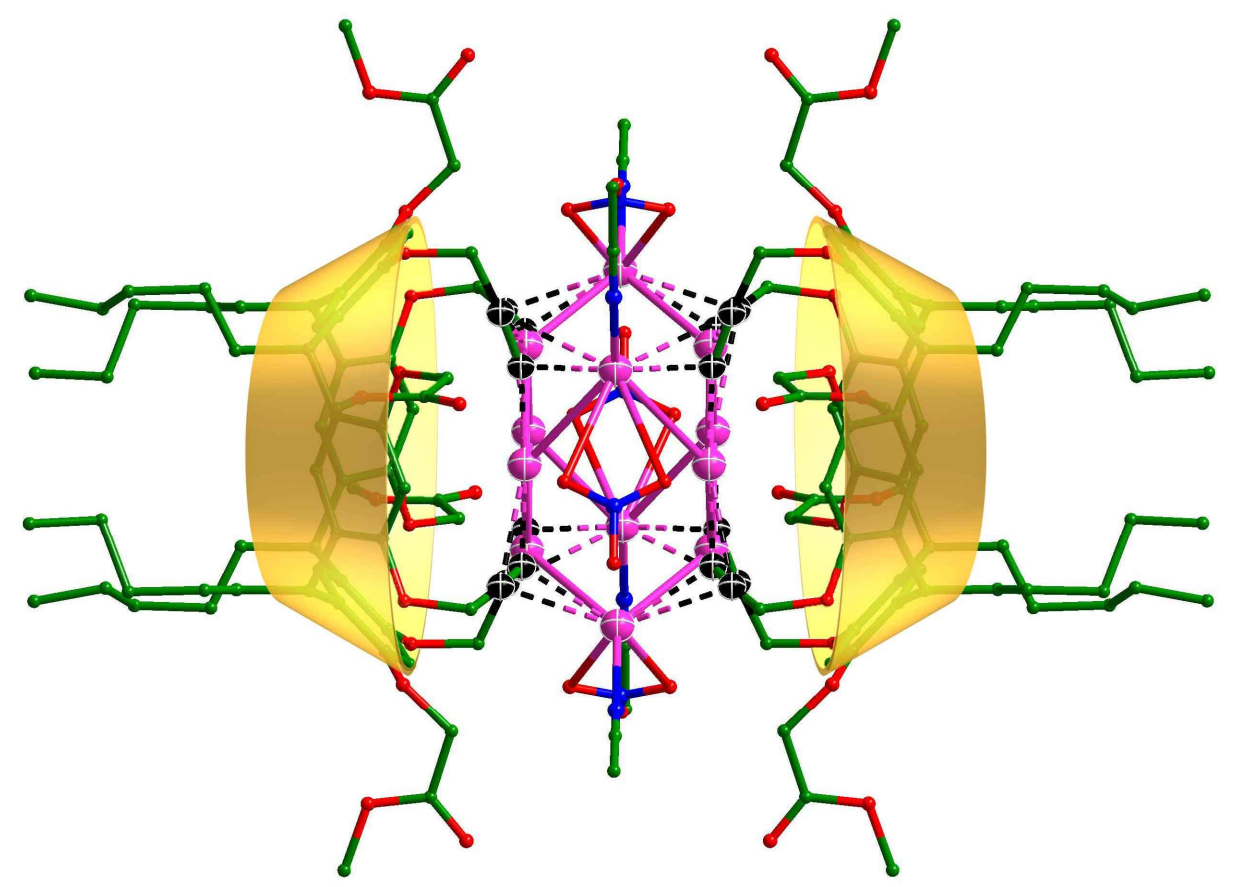

(a)

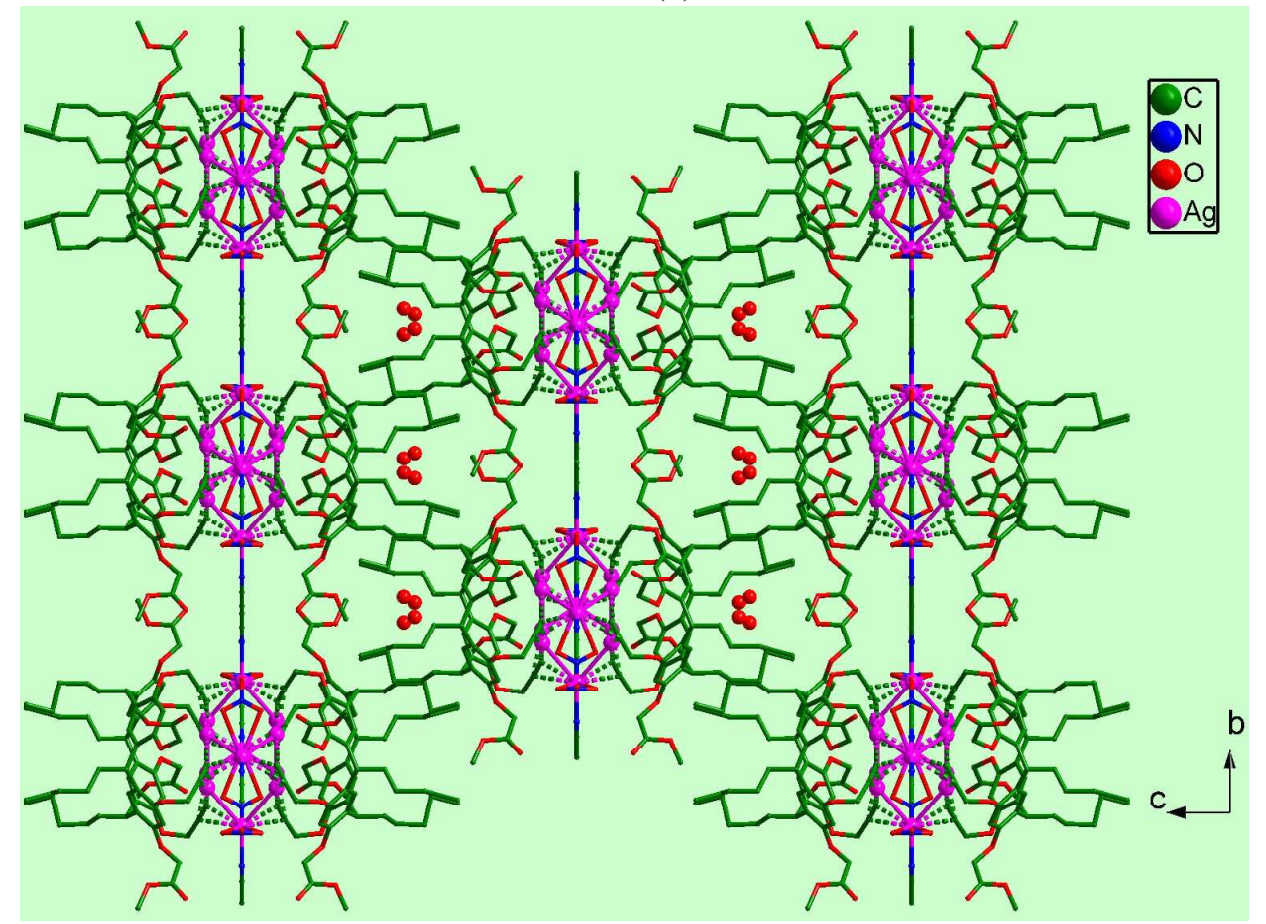

(b)

Figure S1. (a) Perspective view of the sandwich-type $\mathrm{Ag}_{12}$ cage embraced by two bowl-shaped resorcin[4]arene tetraethynide units in $\mathbf{1}$. The coordinated nitrate and acetonitrile ligands are shown. The hydrogen atoms and lattice water molecules are omitted. (b) Perspective view of the packing structure of $\mathbf{1}$. The disordered lattice 
water molecules are shown as red balls.

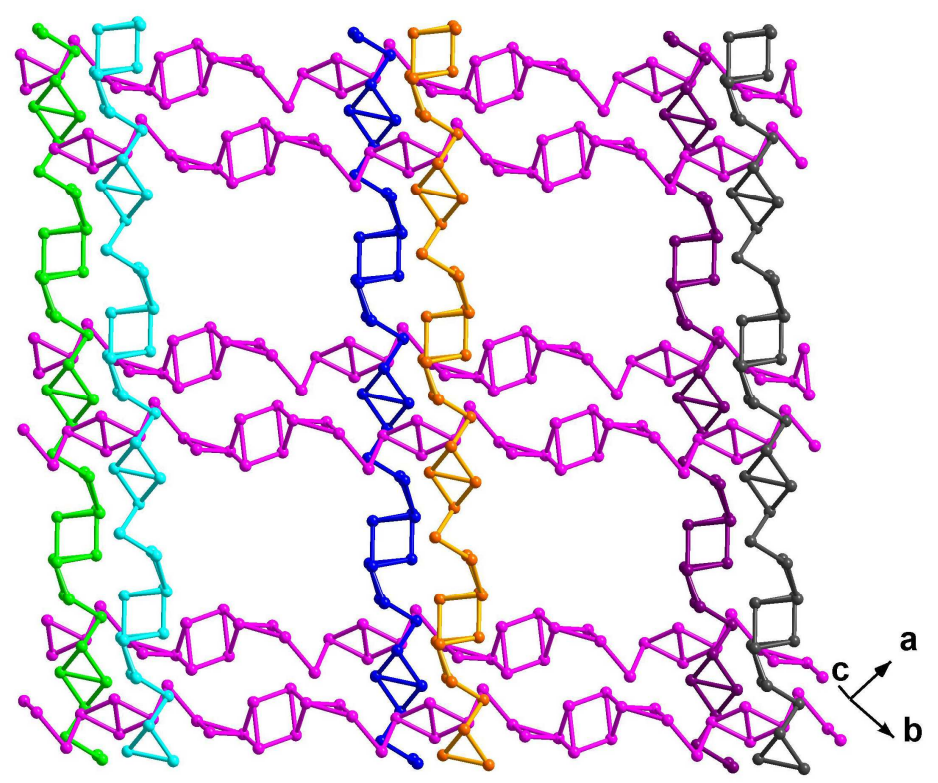

Figure S2. Intersected packing manner of adjacent silver(I) chains in 2.

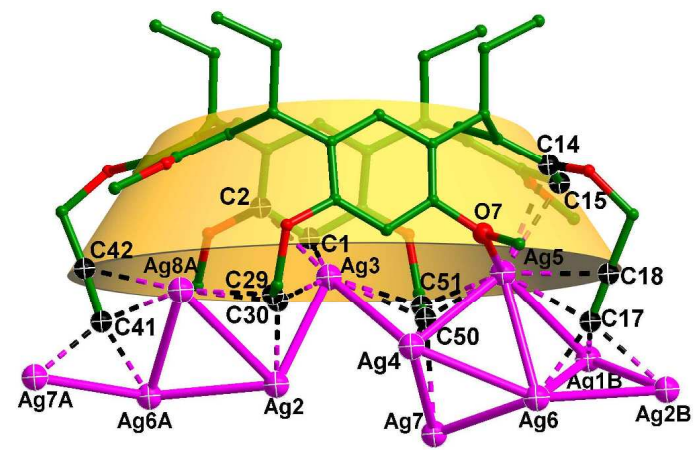

(a)

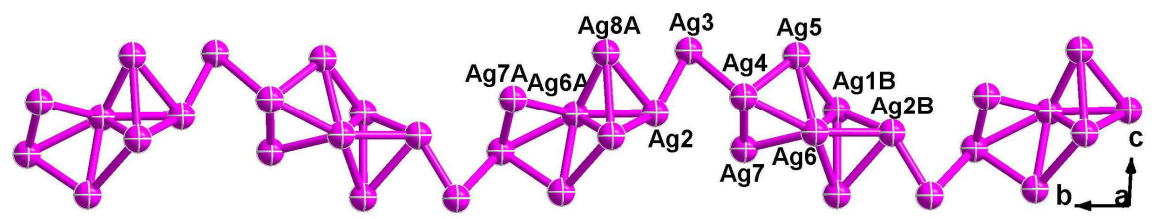

(b)

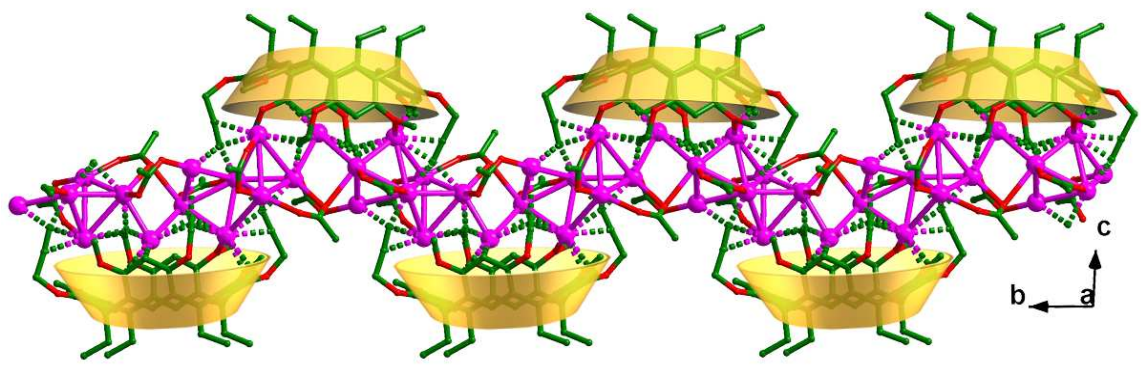

(c) 
Figure S3. (a) Coordination modes of the ethynide groups on the $\mathrm{L} 3^{4-}$ anion with atom labeling in 4. (b) Characteristic cationic silver(I) chain formed from the linkage of adjacent $\mathrm{Ag}_{11}$ aggregates via argentophilic interactions. (c) Infinite zigzag silver(I) chain alternately decorated by the bowl-shaped resorcin[4]arene tetra-ethynide units via $\mathrm{Ag} \cdots \mathrm{C}$ bonds. Hydrogen atoms, fluorine atoms and acetone molecules are omitted for clarity.

\section{Electrochemical properties}

The electrochemical properties were also studied for $\mathbf{3}, \mathbf{4}$ and $\mathrm{AgCF}_{3} \mathrm{CO}_{2}$. Cyclic voltammograms of $\mathbf{3}$ and $\mathbf{4}$ exhibit quasi-reversible redox couples $E_{\mathrm{c}} / E_{\mathrm{a}}\left(E_{\mathrm{c}}\right.$ and $E_{\mathrm{a}}$ are cathodic and anionic peak potentials, respectively) of $350 \mathrm{mV} / 1100 \mathrm{mV}$ and 250 $\mathrm{mV} / 1000 \mathrm{mV}$, respectively. These peaks are very similar to the redox couples of $\mathrm{AgCF}_{3} \mathrm{CO}_{2}\left(E_{\mathrm{c}} / E_{\mathrm{a}}\right.$ of $\left.200 \mathrm{mV} / 1200 \mathrm{mV}\right)$ (Figure S4). Thereby, the redox peaks for 3 and 4 mainly account for the redox process of $\mathrm{Ag}^{+} / \mathrm{Ag}$ couples. The different $E_{\mathrm{c}}$ and $E_{\mathrm{a}}$ values also demonstrate that the bulk ethynide functionalized resorcin[4]arene ligands probably play a role in affecting the redox behaviors. Controlled-potential electrolyses of $\mathbf{3}$ and $\mathbf{4}$ show a consumption of 8 electrons per molecule, respectively. These multi-electron transfer processes also hold promise for the generation of mixed-valent silver(0,I) materials by electroreduction of multinuclear silver(I)-alkynyl complexes.

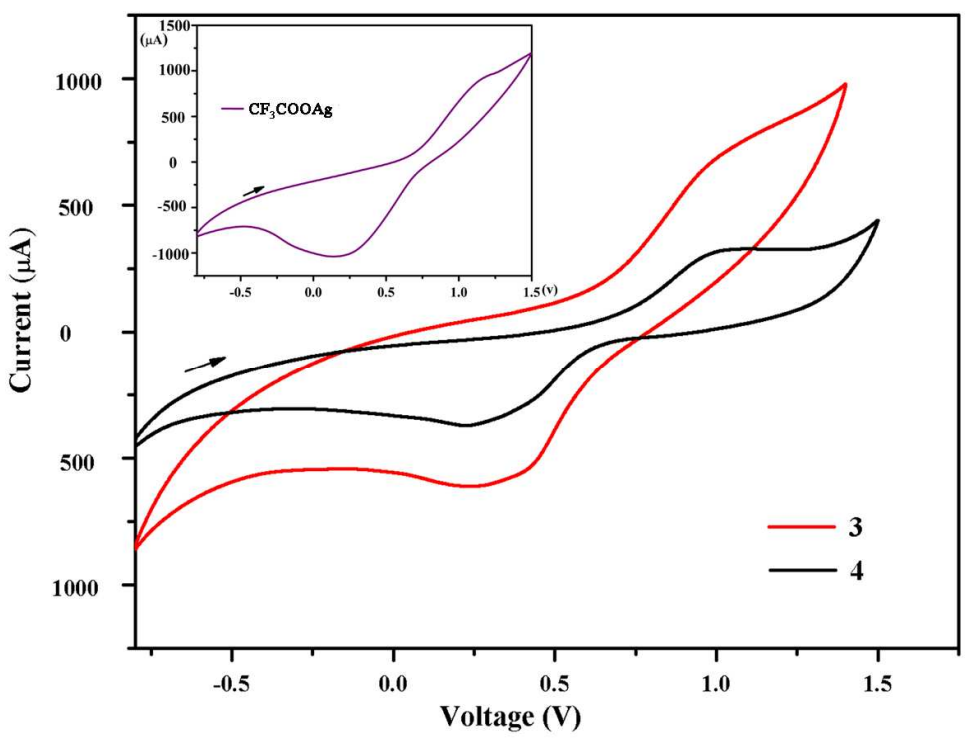


Figure S4. Cyclic voltammograms for 3, 4 and $\mathrm{AgCF}_{3} \mathrm{CO}_{2}$ in methanol solutions containing $1 \mathrm{~mol} / \mathrm{L} \mathrm{LiClO}_{4}$ and $0.5 \mathrm{~mol} / \mathrm{L} \mathrm{CF}_{3} \mathrm{COOH}$.

\section{Luminescence}

The luminescent properties of $\mathrm{H}_{4} \mathrm{~L} 2$ and complex 3 were studied in the solid state at room temperature. As shown in Figure S5, the main emission peak of the free $\mathrm{H}_{4} \mathrm{~L} 2$ ligand is at $525 \mathrm{~nm}$ upon excitation at $370 \mathrm{~nm}$, which is probably from the $\pi^{*} \rightarrow \pi$ or $\pi^{*} \rightarrow n$ transition. Complex 3 exhibits an emission peak at $526 \mathrm{~nm}$ upon excitation at $363 \mathrm{~nm}$, which is very close to that of the free $\mathrm{H}_{4} \mathrm{~L} 2$ ligand. Thereby, the emission of complex $\mathbf{3}$ is probably attributed to ligand-to-ligand charge transition.

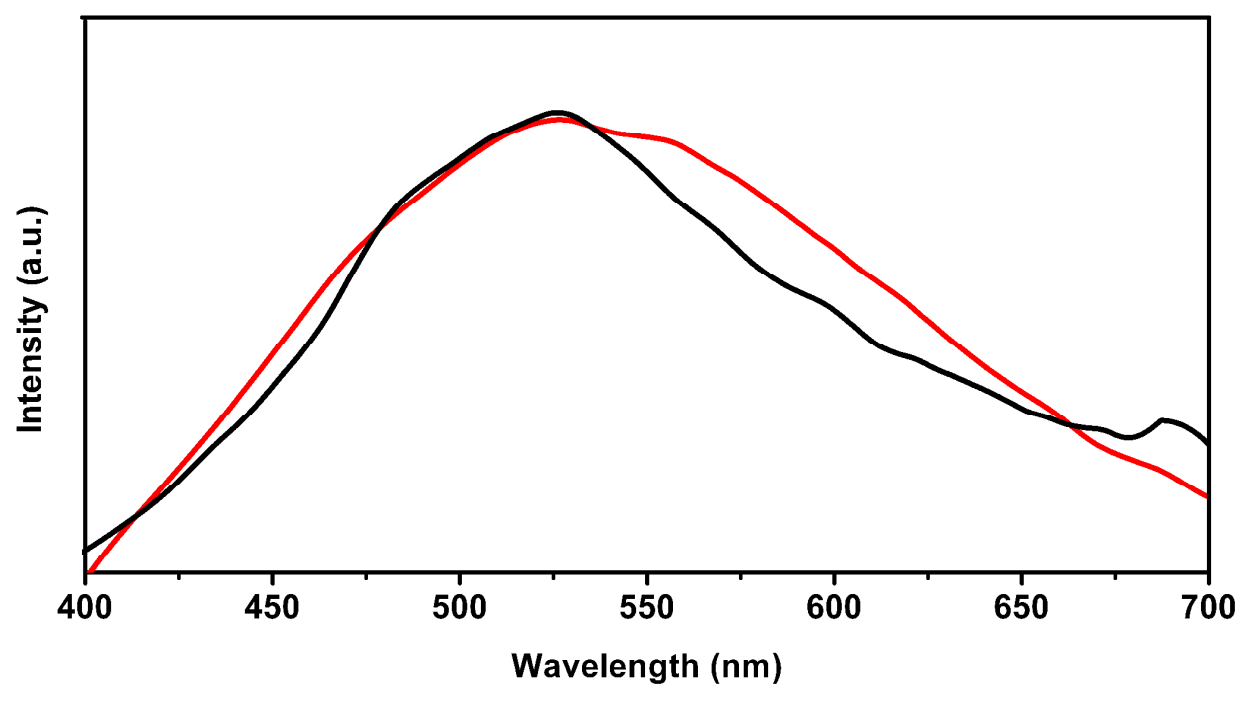

Figure 5. Solid state luminescence spectra of $\mathrm{H}_{4} \mathrm{~L} 2$ (red) and complex 3 (black) at room temperature. 